\title{
Whose Values are you Living when you're Living your Values? An Existential Approach to Values Clarification Coaching
}

\author{
Julian Humphreys \\ Toronto, Canada
}

\begin{abstract}
In this paper, I challenge the claim made by a leading coach training organization that values are intrinsic, unique and fixed over the course of a lifetime. Drawing on the work of existential philosophers, particularly Heidegger, I show how values are instead contingent on multiple forces that surround the individual and over which the individual has some, albeit limited, control. In Part I, I distinguish between values clarification coaching and other kinds of coaching. In Part II, I introduce existentialism, showing how its focus on essential questions of existence and how we might answer those questions makes it a suitable framework for understanding individual values. In Part III, I look at how the work of Kierkegaard and Nietzsche led to a 'subjective turn' in philosophy, and in Part IV, I look at some of the conceptual tools Heidegger developed to determine subjective truth. In Part V, I explore the hidden origins of subjectivity, and how collective subjectivity changes over time, before concluding with a discussion of what an existential approach to values clarification looks like in practice.
\end{abstract}

Keywords: existentialism, values clarification coaching, Heidegger, Kirkegaard, Nietzsche, subjectivity

\section{Introduction}

Values are not chosen. They are intrinsic to you. Your individual values are as distinctly yours as your thumbprint (Glossary, CTI). ${ }^{1}$

The conception of values articulated above, by one of the largest and most respected coach training organizations in the world, is challenged in this paper. Drawing on the work of existential philosophers, particularly Heidegger, I show how values are contingent on multiple forces that surround the individual and over which the individual has some, albeit limited, control. This, in turn, has implications for how values clarification coaching is taught and practiced.

\footnotetext{
${ }^{1}$ As with most claims made by CTI in their training materials, this is simply asserted, without citation or argument.
}

This is an Open Access article distributed under the terms of the Creative Commons Attribution (CC BY) License which permits use, distribution and reproduction in any medium, provided the original work is properly cited. 
The paper is structured in five parts. In Part I, I distinguish between values clarification coaching and other kinds of coaching, situating other kinds of coaching within a pragmatic tradition of 'whatever works,' and values clarification coaching outside that tradition by virtue of the fact that 'whatever works' can only ever be measured from within a pre-existing values orientation. In Part II, I introduce existentialism, showing that its focus on essential questions of existence and how we might answer those questions makes it a more suitable framework for exploring individual values. In Part III, I look at how the work of Kierkegaard and Nietzsche led to a 'subjective turn' in philosophy, and in Part IV, I look at some of the conceptual tools Heidegger developed to determine subjective truth. In Part V, I explore the hidden origins of subjectivity, and how collective subjectivity changes over time, before concluding with a discussion of what an existential approach to values clarification coaching might look like in practice.

In the course of the paper I hope to convey the extent to which Heidegger addresses many of the subtleties and complexities of our inner experience. He is not interested in establishing objective truth, but rather in exploring subjective truth, making him valuable for professional coaches, who for the most part emphasize 'resonance' over 'rightness,' leaving objective truth to others while exploring the nuances and subtleties of individual experience, including the many different perspectives subjectivity contains (some of which may be 'objective').

There is, then, I believe, a natural 'resonance' between Heidegger's philosophy and coaching. Indeed, it wouldn't be too much of a stretch to say that coaching at its best is 'Applied Heidegger.'

\section{I: The Limits of Pragmatism}

Coaching is for the most part a pragmatic activity. Identify a goal, enact a process to support the achievement of that goal, and if that process works (i.e. a direct line can be drawn between the process enacted and the goal achieved) then job well done (assuming ICF ethical guidelines have not been breached). In other words, the goals designed between coach and client at the outset of the coaching relationship serve as the ground of the coaching. There is no larger purpose to which the coaching is oriented than that negotiated between coach and client.

There is, however, a problem here, because if the coaching is to be in any way a meaningful exercise it must refer to something outside of itself, to some 
larger purpose that exists independently of the two (or more) parties involved. Without that purpose, there is nothing for the coaching relationship to serve. For this reason, many coaches spend time in the early stages of a coaching contract doing values clarification work.

Values, it is believed, are the solid ground upon which meaningful goals for the coaching - and for the client's life more generally - are built. But where do values come from, and how can we be sure they are ours, and not someone else's?

Pragmatism may be helpful here, but not really. If a client says, "Valuing relationships and family seems to have worked for me, so I'll go on valuing them," we're failing in our duty as coaches if we don't ask what criteria the client is using to assess what works. Because embedded in those criteria are the client's values. If by 'works for me' she means 'allows me to lead an easy life, unbothered by conflict' then 'leading an easy life unbothered by conflict' is one of the client's values. Or if she means 'allows me to feel warm and fuzzy in my body most of the time' then 'feeling warm and fuzzy in my body most of the time' is one of the client's values. In other words, 'what works' can never justify values, because values pre-exist any account of 'what works.' Consequently, pragmatism cannot by itself serve as a ground for meaningful coaching.

We must, then, turn to some other philosophical tradition to support values clarification coaching; a tradition that offers insight in to how we come to value certain things over others, that recognizes both the limitations and possibilities of free choice when it comes to values, and that is committed to our lives being as meaningful as possible, given the circumstances. That tradition is, I believe, Existentialism, and in the remainder of this paper I look at the work of existentialist philosophers, especially Heidegger, in an attempt to answer the question, 'How do I know that the values I'm living are truly mine and not someone else's?'

\section{II: Existentialism as a Framework for Values Clarification Coaching}

Existentialism is less a philosophy and more a way of doing philosophy (McQuarrie, 1973, p. 14). Although there is a great diversity of belief among existential philosophers - some are religious (Kierkegaard, Buber), others not (Sartre, Nietzsche) - they share a common focus, which includes: 
Individual experience

Existentialist philosophers are not looking to make grand claims about the world. Rather they are looking to clue us in to various aspects of our individual experience that we may not currently be aware of.

\section{Feelings and actions}

Earlier philosophers, most notably Descartes, privileged thought above all else. In contrast, existentialists see humans as first and foremost 'existents' (as opposed to thinking subjects), where existence precedes essence. That's to say, "man first of all exists, encounters himself, surges up in the world - and defines himself afterwards" (Jean-Paul Sartre in McQuarrie, 1973, p. 15). In this sense Descartes Meditations are simply one man's account of his own self-definition, not a generalizable account of human essence.

\section{Death as not only inevitable but potentially imminent}

Insofar as existentialists are interested first and foremost in existence, they are necessarily interested in its opposite - death.

\section{Authenticity as a goal}

Given the inevitability of death, the question of how to make the most of life becomes a central theme in existentialism, with a particular focus on the question, "How do I live authentically, as me, as opposed to as someone else?"

\section{Anxiety or Angst}

Insofar as humans are free to choose how they live, they are liable to experience a range of difficult emotions associated with that freedom, in particular anxiety or angst.

Existentialism recognizes, validates and celebrates inner experience, especially where that inner experience is rich, changeable, and mooddependent. "The existentialist stresses knowledge by participation, the empiricist knowledge by observation" (McQuarrie, 1973, p. 27). Existentialists hold that the empirical study of human beings, while useful, does not go far enough in capturing important aspects of human existence that can only be made available to others through a more subjective, inward-looking approach.

Thus, it is the task of the existentialist philosopher to attempt to make sense of life in its completeness, both as it is lived and experienced individually, and as part of a community. Existentialists ground their philosophies in their own experiences of life and death, of freedom and responsibility, of guilt and anxiety, in an attempt to make sense of their own 
lives and the lives of those around them. In so doing they grapple with questions that we often shy away from, including:

- Who am I?

- What is my true nature?

- What is my purpose in life?

- How should I live?

questions that raise the additional question:

- How - by what means or method - can I best answer these questions?

Existential philosophy is thus as much concerned with form as it is with content - with 'how' as much as 'what'.

\section{III: The Importance of Subjectivity}

Søren Kierkegaard, widely credited as the first existentialist philosopher, wanted to free people from the "illusion of objectivity" (Warnock, 1970, p. 7). Kierkegaard believed that objectivity, by which he meant the capacity to adopt or discover general laws, robs people of their capacity for subjectivity, which is necessary for spontaneity, individuality, personal freedom, and enlightenment. It is this emphasis on subjectivity that distinguishes existentialist philosophy from the Cartesian philosophy that preceded it.

Subjective knowledge has three essential characteristics:

1. It cannot be passed on from one person to the next

2. It is inherently paradoxical

3. It is concrete, not abstract

For Kierkegaard, what's important is less what is thought, and more how something is thought. If it is thought by a concrete, individual thinker, then it is a thought worth having. If it is a rule-bound, abstract thought, it is a "thought without a thinker" (Kierkegaard in Warnock, 1970, p. 10), with little relevance to anyone, even though it may appear to be relevant to everyone. In other words, the only thought that matters for Kierkegaard is one that arises in a particular time and place for a particular individual, for which the thinker is ultimately responsible. As Mary Warnock puts it, "The truth exists for you and 
it exists for me, but each of us must grasp it for himself" (Warnock, 1970, p. 12).

Friedrich Nietzsche took Kierkegaard's circumspect view of objectivity further, claiming there simply is no such thing as objective knowledge. We experience the world through a cognitive apparatus that is already steeped in subjectivity, whether we know it or not. "Our very sense-perceptions are altogether permeated with valuations" (Nietzsche in Warnock, 1970, p. 14). We cannot experience, let alone describe, the world without bringing value judgments to bear on it, and consequently there are no objective 'facts' about the world.

As a result, we are each responsible for our own reality, experientially and morally. The categories I use to describe the world shape my experience of the world, and the moral laws I choose for myself shape my behavior. Neither I nor anyone else is in a position to make general claims about how the world is or how we should behave. "The law my will creates is a law for me and me only" (Warnock, 1970, p. 19).

To fully embrace this freedom, however, is anxiety-inducing. It requires foregoing easy answers based on received opinion and finding one's own unique way of being human. "The only obedience to cultivate is obedience to one's own ideal" (Warnock, 1970, p 22). But how can I know or develop my own ideal, when I am so inextricably tied to others?

Nietzsche does offer a 'method' of sorts for getting to know ourselves as discrete individuals. In Untimely Meditations, he writes:

Let the youthful soul look back on life with the question: what have you truly loved up to now, what has drawn your soul aloft, what has mastered it and at the same time blessed it? Set up these revered objects before you and perhaps their nature and their sequence will give you a law, the fundamental law of your own true self. Compare these objects one with another, see how one completes, expands, surpasses, transfigures another, how they constitute a stepladder upon which you have clambered up to yourself as you are now; for your true nature lies, not concealed deep within you, but immeasurably high above you, or at least above that which you usually take yourself to be. (Nietzsche, 1988, p. 129)

The problem, however, is in implementing his 'method.' Most of us have, unfortunately, lost the ability to turn inward and discover what "has drawn [our] soul aloft, what has mastered it and at the same time blessed it." We have been 
taught to value religion and/or the objective sciences to such a degree that we are no longer able to access our subjectivity, even when we want to.

As a result, we live according to the values and beliefs of the herd, differentiating ourselves only in marginal ways that have no real significance. We become, as Rollo May put it in the 1950s, hollow people, with no clear sense of what we need or want. We look to others to provide answers when only we ourselves can answer those questions, by ourselves, for ourselves, by turning inward.

The modernist emphasis on objectivity and rationality, and its precursor, religion, have thus robbed us of the ability to distinguish ourselves from others. We dismiss subjective experience to the point that we are no longer able to access what is truly unique about ourselves, and as a result are plagued with anxiety, with the sense that we are not living the life we could live, or are meant to live; not making the contribution we are truly capable of making. As Andre Gide put it:

The part in each of us that we feel is different from other people is just the part that is rare, the part that makes our special value - and that is the very thing people try to suppress (Gide, The Immoralist)

In other words, a society that values faith and/or objectivity above all else leads us to lose touch with what makes us unique, the source of our greatest possible contribution. For things to be otherwise - for the most valuable part of us to be realized - the modernist emphasis on objectivity, and the pre-modern emphasis on faith, in education and society more generally, must be offset by an equal or greater emphasis on subjectivity.

\section{IV: Tools for determining subjective truth}

Since Nietzsche there has been a greater emphasis on subjectivity in education and society. We are more likely to say things like 'You have your truth, and I have mine,' but this emphasis alone is not enough. Just as we need sophisticated tools for determining objective truth - philosophical logic, experimental methods, technologies that enhance our perceptual and observational abilities - so we need equally sophisticated tools for determining subjective truth. It is, after all, the increasing sophistication of our tools for determining objective truth that has led to the incredible advances in science and technology that we have seen in the past four hundred years; and it is the lack of such sophisticated tools for determining subjective truth that has led, at 
best, to relativism, nihilism, apathy, and boredom, and at worst, prejudice, ignorance and hate.

Although Nietzsche's provocative aphorisms are tools of a sort for determining subjective truth, the work of German philosopher Martin Heidegger offers a more systematic approach. He uses a phenomenological method that rejects rationalism in favor of an individual's lived experience.

Lived experience has as its central feature, according to Heidegger, an awareness of its own existence in any given moment. This is a particularly human phenomenon, and Heidegger used the word Dasein (trans: "being there") to refer to this 'being' that is capable of recognizing its own existence. Instead of talking about human beings, then, he spoke of Dasein, because that word better captures the extent to which we are "always in the world, in space, in time, in the body, emotionally 'attuned' (gestimmt), intersubjective and limited by death" (Cohn, 1997, p. 13). In other words, our consciousness is always grounded in a particular way of being in a particular time and place, and thus there is no such thing as an experience of the world that is not inherently subjective.

Heidegger then distinguishes between two forms of inquiry into our subjective experience - ontic and ontological.

1. Ontic inquiry is concerned with the particular way in which I as an individual am in the world.

2. Ontological inquiry is concerned with the particular way we come to experience ourselves as individuals in the world.

Ontological inquiry is still an inquiry into subjective experience, because our subjective experience of the world, even collectively, is formed through our collective being in the world. In other words, what we may take to be universal ways of being - objective facts about how we are or how the world is - are in fact a product of time and place and the particular ways we have collectively come to be as subjective beings.

As Dasein, then, uniquely aware of our own being, we are faced with the daunting tasks of not only making sense of our own individual subjectivity who am I and what am I about? - but also our collective subjectivity - who are we and how did we come to be as we are? I experience the world as I experience it (ontically) but to what extent is this experience of the world a 
result of the way in which my subjectivity has been formed by forces beyond my control and of which I may have very little to no awareness (ontologically)?

Many of the tools Heidegger develops for determining subjectivity being-in-the-world, thrownness/facticity, being-in-the-world-with-others, spatiality, temporality, embodiment, mood, and mortality - can be applied both ontically and ontologically. In the next section I address each of these in turn as they are applied ontically, before looking to see how Heidegger's philosophy can be applied ontologically.

\section{Being-in-the-world}

Heidegger invented new words, including many hyphenated terms, to capture realities that our language hitherto ignored. Being-in-the-world is designed to capture the fact that, as a human being, I am involved with the world. I am not simply a disengaged consciousness, going about my business in a perfectly rational way, as Descartes imagined. I care about the world, am invested in it - or at least in my experience of it. What each individual cares about may vary from person to person - but we all care about something. For even when we seem not to care, we care enough not to care. In other words, the world and our experience matters - to us, if to no one else.

\section{Facticity}

As a being-in-the-world I am 'thrown,' by which Heidegger means I find myself in a particular situation with specific possibilities. Heidegger uses the word 'facticity' to describe the specific-ness of my situation. I exist in a 'world,' where that world consists of a particular environment with certain givens - a genetic inheritance, a family background, a nationality, a social and political context. The extent to which I recognize and accept these givens impacts how authentic I can be.

\section{being-in-the-world-with-others}

For Heidegger, our existence is necessarily relational. We are always in the world with others, whether we like it or not. This has several consequences:

1. We may care too much for others, 'leaping in' and robbing them of their ability to experience themselves for themselves. 
2. We may care too much about what 'they' - the nameless, faceless masses - think about us, leading us to compromise our originality for the sake of fitting in.

Consequently, we need to learn how to be in relation with others in such a way that both our own and others' ability to be open to the world is maintained.

\section{Spatiality}

For Heidegger spatiality is less about physical space and more about the psychological experience of closeness and farness. Objects can be near or far in physical space, but that does not directly map on to our experience of objects as near or far.

\section{Temporality}

Similarly, time is experienced not linearly, as a clock represents it, but as a mixture of past, present and future. I live toward the future, but in the vision of the future that I hold is my past. At the same time, and in every moment, I am free to choose my relationship with the past, so I can live toward a different future.

\section{Mood}

For Heidegger, we always experience the world from within a particular mood. There is no 'non-mood' way of experiencing the world, as one mood can only be replaced by another. We can, however, become more aware of how our moods impact our experience, and how our experience impacts our moods, such that we achieve some degree of mastery over our moods.

\section{Mortality}

For Heidegger, our mortality is not some distant inevitability, but an always present possibility. Only when we accept that at any moment we may die, and that we may die alone, are we truly able to live freely and authentically, neither subject to nor rejecting of the constraints imposed upon us by others.

For Heidegger, then, our authenticity is contingent on our recognizing that we are engaged beings-in-the-world, who care, who are 'thrown' into a world with specific givens, who exist relationally, who experience time and space subjectively, who see the world through ever changing moods, and who live toward a death that is not only inevitable but may come at any time. 
This is to apply Heidegger's tools ontically, to our own subjective experience of life compared with others in our world. But there is another way of applying Heidegger's tools, one that focuses less on discrete individuals as they differ from one another in their subjectivity, and more on discrete cultural epochs and the different subjectivities they allow for. In the next section I explore this more ontological dimension of Heidegger's philosophy.

\section{V: The Origins of Subjectivity}

For Heidegger, we are thrown not only into a particular situation vis a vis others that surround us, but also vis a vis others who are wholly absent, because they existed (or will exist) in another culture or epoch that is inaccessible to us. As a result of their absence we rarely, if ever, confront the specificity of our own situation as it relates to these absent others, and consequently take for granted much of what is present in our own situation.

Consequently, we take as given certain aspects of our subjectivity, seeing them as necessary or essential, when in fact they are highly contingent. Even philosophy, which aims to be unbiased and reflexively aware of its own assumptions, is never neutral, because it arises out of a history that is just one of many possible histories. Consequently "we never rise above our environment to some pure, lofty pedestal and pass judgment on the world, as if we were untainted by it" (Harman, 2007, p. 31).

In practice, this means that our subjectivity is formed within the constraints imposed upon it by the historical contingencies that preceded its development, such that we can never truly see for ourselves, free of the influence of others. Even philosophers are forced to either embrace, reject, modify or deconstruct the ideas of those who came before them. There can be no primitive philosophy, just as there is no pure subjectivity or direct experience of the world. The very medium through which we experience the world - subjectivity - is culturally shaped.

In order to know ourselves, then, we need to uncover the hidden layers of our conscious experience. We need to see how our experience of the world is structured within a particular worldview, which includes basic presuppositions specific to a particular time and place. These presuppositions are embedded in what Heidegger calls 'originary language.'

Heidegger distinguishes between two kinds of language: 
1. Originary language orients us to the world. It speaks prior to us speaking. It is "the articulation prior to any human speech that makes salient particular features of the world by setting things into a certain structure. It is a kind of pointing out or showing, a highlighting of certain things and not others" (Wrathall, pp. 90-91). It is not a language in the traditional sense of words and expressions, but rather a rich collection of various sounds and images that together create a 'feel' for the world.

2. Ordinary language, on the other hand, is the everyday language we use to express the ideas we have about the world, ideas that arise within the context and against the backdrop of originary language.

Our values and judgements are thus a direct consequence of our originary language, such that even what we take objects to be, in and of themselves, is informed by originary language. A person living in a religious culture, for instance, interprets objects as having religious significance, in and of themselves, whereas a person living in a capitalist society interprets objects as having economic significance, in and of themselves. In other words, what we take to be the essence of objects changes depending on the originary language through which we see the world. Consequently, as originary language changes over time, so does our experience of the world, to the point that it makes no sense to speak of objects having fixed properties. The essence of an object is determined by the originary language within which it is perceived.

Originary language can thus be said to not only create our experience of the world, but to create worlds themselves, as we experience them. It speaks to us "before we are speaking" (Wrathall, 2005, p. 97). It shapes who we are, what we experience, and how we perceive, think, and act.

If we are to live authentically, then, we must not only be able to define ourselves in relation to others (applying Heidegger's tools ontically) but also in relation to the larger cultural reality of which we are a part (applying Heidegger's tools ontologically). One way to think of this is using a computer metaphor, with originary language being the operating system, and ordinary language the programs that run on that operating system. We can do various things with the programs that run on an operating system - but what we can do is constrained by the limits placed on those programs by the operating system. Only by intervening at the level of the operating system do new, previously unavailable possibilities open up. 
So how do we become active agents with respect to originary language?

Charles Spinosa, Fernando Flores and Hubert Dreyfus (1997), in their book Disclosing New Worlds, identify three ways that originary language (what they call the 'style' of a culture) changes over time. Below I show how coaching developed as a result of incremental changes in originary language.

\section{Articulation}

Articulation is when an originary language is brought into sharper focus, with what was once implicit becoming explicit. Coaching experienced a moment of articulation when, in 1995, the ICF was formed. Prior to that various people experimented with what we now call 'coaching conversations,' but its norms were implicit, rather than explicit. Subsequent to the formation of the ICF the originary language of coaching came into sharper focus as the values, assumptions and standards embedded in that originary language were put in the ordinary language of ICF Core Competencies and a Code of Ethics.

\section{Reconfiguration}

Reconfiguration is when a practice that is marginal in one cultural reality becomes dominant in another. For example, positive psychology was marginal within the field of academic psychology, before being reconfigured as central within the field of coaching.

\section{Cross-appropriation}

Cross-appropriation is when a practice is appropriated by a culture that would not have developed that practice organically, but that it nevertheless finds useful. Coaching is rife with examples of cross-appropriation. The shifts from sports to life coaching, from life coaching to leadership coaching, and from leadership coaching to team coaching, all represent examples of crossappropriation.

What all these changes have in common is that they are the result of engaged beings-in-the-world acting within and between established cultural realities, for the sake of expanding the range of subjectivities available to us, with the result that more people are able to live authentically. 


\section{Conclusion}

So what, then, are the implications of a more existential understanding of values for coaches? What does an existential approach to values clarification coaching actually look like in practice?

Based on the discussion above, an existential approach to values clarification coaching would, at a minimum, include the following:

1. A process designed to identify what the client cares about. This could include visualizations, assessments, and other reflective practices.

2. A clear acknowledgment of the client's facticity. This is often ignored by coaches, who are trained to focus on possibility, often at the expense of facticity. Many coaches ignore signals that the client wants to talk about facticity by interpreting all allusions to limits as 'saboteurs.'

3. The development of critical thinking skills, especially as these relate to:

a. cultural norms around class, race, gender, sexuality and other identity positions

b. societal norms around social, political and economic systems that impact individual subjectivity, especially capitalism and technology

4. Developing the client's awareness of how the future inheres in the past and the past inheres in the future, including a focus on what the client's narrative is, and how the narrative is constructed.

5. Expanding the client's awareness of moods and how to manage them effectively

6. A frank discussion of death, not as a distant inevitability but as an always present possibility.

In addition, an existential approach to values clarification coaching would empower clients to expand the range of values available to themselves and others through articulation, reconfiguration and cross-appropriation.

Values clarification coaching of this kind would ground clients in their own deepest sense of self, while at the same time recognizing that this sense of self is inherently limited by the realities they find themselves in. And it would empower them with the tools to change those realities, for themselves and others, wherever possible. 


\section{References:}

Atwood, G. \& Stolorow, R. (1984). Structures of subjectivity: Explorations in psychoanalytic phenomenology. Hillsdale, NJ: The Analytic Press.

Cohn, H. (1997). Existential thought and therapeutic practice. London: Sage.

CTI Glossary. Accessed on $1^{\text {st }}$ August 2016 at www.thecoaches.com/learninghub/fundamentals/res/FUN-Tools/Glossary.docx

CTI Six ways to clarify values. Accessed on $1^{\text {st }}$ August 2016 at http://www.coactive.com/learninghub/intermediate/fulfillment/res/Topics/FUL-Six-Ways-To-ClarifyValues.pdf)

Harman, G. (2007). Heidegger explained: From phenomenon to thing. Chicago: Open Court.

Hass, L. (2008). Merleau-Ponty's philosophy. Bloomington: Indiana University Press.

Heidegger, M. (1996). Being and time. J. Stanbaugh (trans). New York: SUNY Press.

MacQuarrie, J. (1973). Existentialism. New York: Penguin.

May, R., Angel, E., and Ellenberger, H. (Eds.). (2004). Existence. New York: Rowman \& Littlefield.

May, R. (1953). Man's search for himself. New York: Delta.

Nietzsche, F. (1968). The will to power. New York: Vintage.

Nietzsche, F. (1988). Untimely meditations. R. J. Hollingdale (trans.) Cambridge: Cambridge University Press.

Nietzsche, F. (1995). Thus spoke Zarathustra. London: Penguin.

Sartre, Jean-Paul. (1946). Existentialism is a humanism. Accessed on $1^{\text {st }}$ August, 2016 at https://www.marxists.org/reference/archive/sartre/works/exist/sartre.htm

Spinosa, C., Flores, F., and Dreyfus, H. (1997). Disclosing new worlds: entrepreneurship, democratic action, and the cultivation of solidarity. Boston: MIT Press.

van Deurzen-Smith, E. (1997/2010). Everyday mysteries. London: Routledge. van Deurzen, E., \& Arnold-Baker, C. (Eds.). (2005). Existential Perspectives on Human Issues. London: Palgrave MacMillan.

Warnock, M. (1970). Existentialism. Oxford: Oxford University Press. Wrathall, M. (2005). How to read Heidegger. London: Granta Books. Yalom, I. (1980). Existential psychotherapy. New York: Basic Books. 